\title{
Thermal cycling aging of encapsulated Phase Change Material - Compressed Expanded Natural Graphite composite
}

\author{
Jérôme SOTO $^{a, b^{*}}$, Mariam JADAL ${ }^{\text {a.b, }}$, Nicolas DE GUYENRO ${ }^{c}$, Didier DELAUNAY ${ }^{a}$ \\ ${ }^{a}$ Université de Nantes, Nantes Atlantique Universités, CNRS, Laboratoire de Thermique et d'Energie de Nantes, \\ UMR 6607, La Chantrerie, rue Christian Pauc, BP 50609, 44306 Nantes Cedex 3, France \\ ${ }^{b}$ Institut Catholique d'Arts et Métiers de Nantes, 35 avenue du Champ de Manouvres, 44470 Carquefou, France \\ ${ }^{\mathrm{c}}$ HUTCHINSON SA, Center for Research \& Innovation, Rue Gustave Nourry, BP 31, 45120 CHALETTE-SUR- \\ LOING - FRANCE \\ * Corresponding author. Tel.: +33240524019 \\ E-mail address: jerome.soto@icam.fr
}

\section{Highlights}

- Delamination appears on CENG-PCM composites after thermal cycling

- Heat transfer performance remains roughly stable during thermal cycling

- Latent heat of the CENG-PCM composite decreases by less than $10 \%$ after cycling

- Phase change temperatures are not affected by aging

- CNEG-RT70HC composite presents a good chemical stability to thermal cycling

\begin{abstract}
A paraffin-Compressed Expanded Natural Graphite (CENG) composite encapsulated in aluminium shell has been thermally aged in a packed bed heat storage tank.

A hydraulic test bed has been settled in order to impose 8500 thermal cycles where the material underwent a phase change at each cycle. The PCM phase change provokes an expansion of the composite structure that might affect the effective thermal conductivity and then the heat transfer rate of the Thermal Energy Storage (TES). This performance has been monitored all along the cycling test showing a non-significant change in heat transfer rate, despite a delamination of the composite within the capsule. This phenomenon has been explained by the delamination that affects mainly the thermal conductivity in the axial direction while the heat transfer from the PCM to the aluminium shell occurs essentially on the planar direction. Indeed, the thermal conductivity in planar direction is approximatively six times higher than on the axial direction. A DSC analysis on new and aged samples showed that the phase change
\end{abstract}


temperatures remained the same and the latent heat magnitude decreased by less than $10 \%$. A FTIR analysis confirms the chemical stability of the PCM-CENG composite after 8500 cycles.

\title{
Keywords
}

- Phase Change Material (PCM)

- Compressed Expanded Natural Graphite (CENG)

- Thermal cycling

- Thermal characterisation

\author{
Nomenclature \\ $C_{p}$ : thermal capacity, $\mathrm{J} . \mathrm{K}^{-1} \cdot \mathrm{kg}^{-1}$ \\ $m$ : mass, $\mathrm{kg}$ \\ $q$ : volumetric flow rate, $\mathrm{m}^{3} . \mathrm{s}^{-1}$ \\ $T$ : temperature, ${ }^{\circ} \mathrm{C}$ \\ $t$ : time, $\mathrm{s}$ \\ $\phi$ : heat transfer rate, $\mathrm{W}$ \\ $\rho:$ density, $\mathrm{kg} \cdot \mathrm{m}^{-3}$
}

\author{
Abbreviations \\ CENG: Compressed Expanded Natural Graphite \\ DSC: Differential Scanning Calorimetry \\ ENG: Expanded Natural Graphite \\ FTIR: Fourier-Transform Infrared Spectroscopy \\ HTF: Heat Transfer Fluid \\ PCM: Phase Change Material \\ TES: Thermal Energy Storage
}

\section{Introduction}

Phase Change Materials (PCM) are commonly used in different applications for heat storage and thermal control in many areas: solar power [1] [2] [3], building [4] [5] [6], domestic hot water [7] [8], electronic [9] [10] [11] [12], smart textile [13], transportation [14] [15] [16] [17], industrial processes [18] [19] [20] etc. In all the applications, the PCM undergoes numerous thermal cycles that can be up to few thousands during their lifetime. A thermal stability is then 
required in order to maintain the performances such as heat storage capacity, thermal conductivity and phase change temperatures.

Some PCM are well characterised for thermal cycling aging [21]. However, when the PCM is associated with a thermal conductive matrix, the literature is less prolific. This association is very often considered in order to enhance the effective thermal conductivity of the PCM [22], to obtain a form-stable material or to reduce the supercooling degree of the PCM [23].

Due to its good thermal conductivity and very high porosity, the Expandable Natural Graphite (ENG) is very frequently chosen as a thermal conductivity enhancement agent [24] [25]. In order to increase the apparent thermal conductivity, the ENG can be compressed [26]. The matrix obtained, called Compressed Expanded Natural Graphite (CENG), can then be impregnated with PCM [27] [28]. Alternatively, when the impregnation of an existing structure by the PCM is not possible, the ENG can be associated with PCM with an impregnation-compression-sintering technique [29] where the PCM and the ENG in dispersed form are mixed before sintering in order to obtain a cohesive composite structure.

A lot of works has been carried out on this form-stable PCM composites [25]. However, most of the time, the thermal stability study is limited to a small number of cycles, i.e., less than a thousand. In addition, the tests are executed on small samples, weighing about a few milligrams, in order to perform cycles and analysis using the DSC device [30] [31]. The main properties studied are usually the phase change temperatures, the chemical stability, and when the sample is large enough, such in Yuan et al. [23] work with erythritol - ENG composites, the weight lost, and in very seldom cases the mechanical properties [32], [33] or the heat transfer capacity [34].

During the thermal cycling, in addition to the chemical stability, the mechanical durability of the conductive structure could affect the thermal conductivity of the composite. Indeed, the matrix deformations due to the PCM density variation whereas the PCM changes phase, might provoke cracks in the conductive structure and then affect the effective thermal conductivity. In order to prevent the loss of the composite integrity and to prevent PCM leakage, the Compressed Expandable Natural Graphite (CENG) can be encapsulated. The encapsulation of PCM is an alternative solution of the thermal conductive enhancement technique for improving heat transfer rate [35]. However, nano [36], micro [37] or macro encapsulations [38] are very rarely associated with an internal conductive matrix [25] [39].

This study tackles the thermal stability of a paraffin-ENG composite encapsulated in aluminium shells in a packed bed heat exchanger configuration. A test bed has been designed and 
manufactured in order to impose 8500 thermal cycles to the composite. The temperatures and

the heat exchange rate were monitored during the cycling test. These data were initially dedicated only for managing the automatic switch between the cooling and heating cycles. However, the data can be exploited to provide a first analysis. After the cycling test, the thermal properties of the CENG-PCM capsules were measured and compared to the material at its initial state.

\section{Experimental set-up description}

\subsection{Materials}

\subsubsection{CENG manufacturing}

Manufactured from exfoliation of natural graphite particles, the Expanded Natural Graphite (ENG) is composed of porous structure in the shape of worms. Before uniaxial compression, the ENG has a density close to $3 \mathrm{~kg} / \mathrm{m}^{3}$ and a porosity larger than $99 \%$. The compression leads to a layered matrix where the worms are orientated and flattened. A second level of porosity, between each layer, is then created [40]. Therefore, the material presents an orthotropic mechanical and thermal properties as shown by Py et al. [41].

The Compressed Expanded Natural Graphite (CENG) used in this study has been provided by MERSEN ${ }^{\circledR}$ with a density of $2000 \mathrm{~kg} / \mathrm{m}^{3}$. The CENG has been impregnated by capillarity

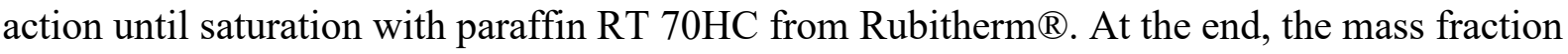
of paraffin was $80 \%$ and $20 \%$ for CENG.

The thermal conductivity of the CENG-PCM has been measured in both directions using a guarded hot plate device designed by Carré and Delaunay [42]. The thermal conductivity in the compression direction is $6 \mathrm{~W} \cdot \mathrm{m}^{-1} \cdot \mathrm{K}^{-1}$ and $20 \mathrm{~W} \cdot \mathrm{m}^{-1} \cdot \mathrm{K}^{-1}$ in perpendicular direction. The paraffin density is $880 \mathrm{~kg} \cdot \mathrm{m}^{-3}$ in solid state and $770 \mathrm{~kg} \cdot \mathrm{m}^{-3}$ in liquid state.

\subsubsection{PCM-CENG-Aluminium Shell}

The thermal expansion of the paraffin when the phase changes, induces an expansion of the CENG. This expansion occurs mainly in the direction of the compression, provoking a separation of the graphite layers. When the expansion motion is bridled during the melting phase, the paraffin escapes preferentially from the CENG through the laminated network created by the graphite layers in the planar direction. In order to prevent the paraffin leaks in the Heat Transfer Fluid, the CENG has been encapsulated in aluminium shells (Figure 1). Each shell encapsulates a bullet shape PCM-CENG material with $13 \mathrm{~mm}$ diameter and $13.5 \mathrm{~mm}$ height. The CENG matrix is oriented to have the bullet axis in the direction of the compression. 
The aluminium capsule, with a thickness of $0.5 \mathrm{~mm}$, has been chosen a little larger with 13.5 $\mathrm{mm}$ diameter and $15 \mathrm{~mm}$ height, in order to leave some free space for the expansion of the composite during the phase change, and then, to avoid paraffin leaks outside the CENG. A thermal conductive paste has been added, in order to reduce the thermal resistance between the composite and the aluminium lateral shell. The amount of grease is small compared to the free space in the capsule in order to leave freely the expansion. The shell has been sealed by laser welding. All the encapsulation process has been designed and performed by HUTCHINSON ${ }^{\circledR}$. The main characteristics of the PCM-CENG-Aluminium composite are displayed in Table 1.

\begin{tabular}{|l|l|c|}
\hline Volume $(\mathrm{ml})$ & & 2.5 \\
\hline $\begin{array}{l}\text { External surface } \\
\left(\mathrm{mm}^{2}\right)\end{array}$ & PCM-CENG-aluminium & 1250 \\
\hline \multirow{3}{*}{ weight $(\mathrm{g})$} & & \\
\cline { 3 - 3 } & Aluminium shell & 1.03 \\
\cline { 2 - 3 } & CENG & 0.36 \\
\cline { 2 - 3 } & PCM & 1.43 \\
\cline { 2 - 3 } & PCM-CENG-aluminium & 2.82 \\
\hline
\end{tabular}

Table 1: Physical parameters for one capsule of CENG-PCM

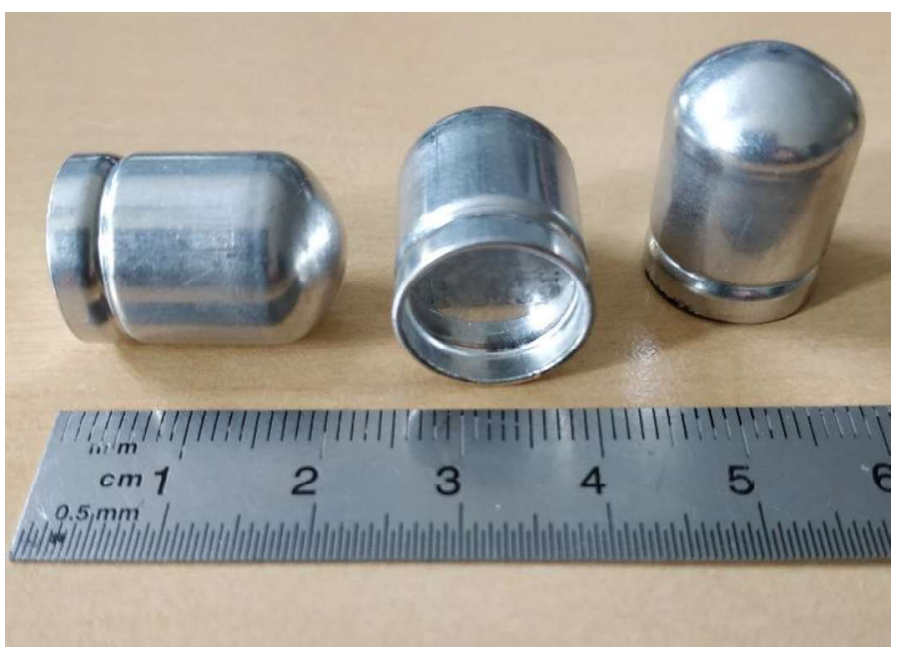

Figure 1 : Picture of CENG-PCM-Aluminium capsules

[single column]

\subsection{Experimental design}

A dedicated hydraulic test bench has been designed and manufactured in order to automatically impose thermal cycles to the packed bed PCM-ENG capsules (Figure 2). The bench is composed of a hot loop where the water is heated with a $6 \mathrm{~kW}$ electric resistance. The cold water is provided by an air-cooled water tank. The two loops operate alternatively using solenoid valves for cooling or heating phases (Figure 3). The system is controlled by an 
ARDUINO program implemented in the electrical box. The circulation is performed using a centrifugal pump where the flow rate can vary from 720 to $7601 . \mathrm{h}^{-1}$.

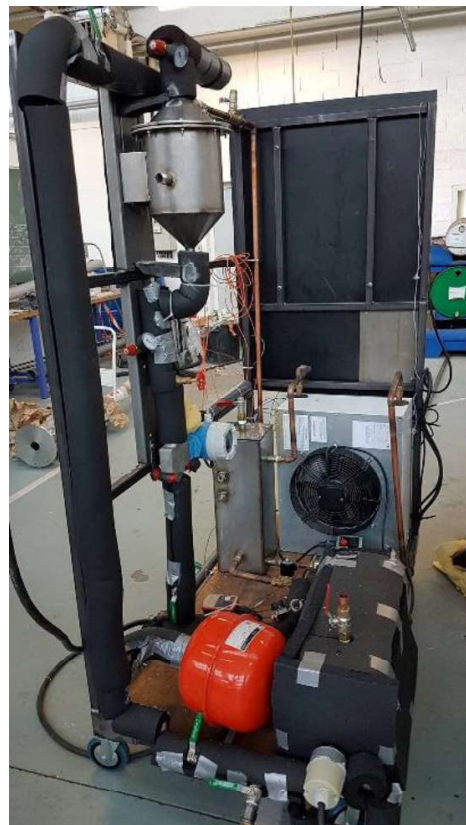

Figure $2:$ Picture of the test bed

[single column]

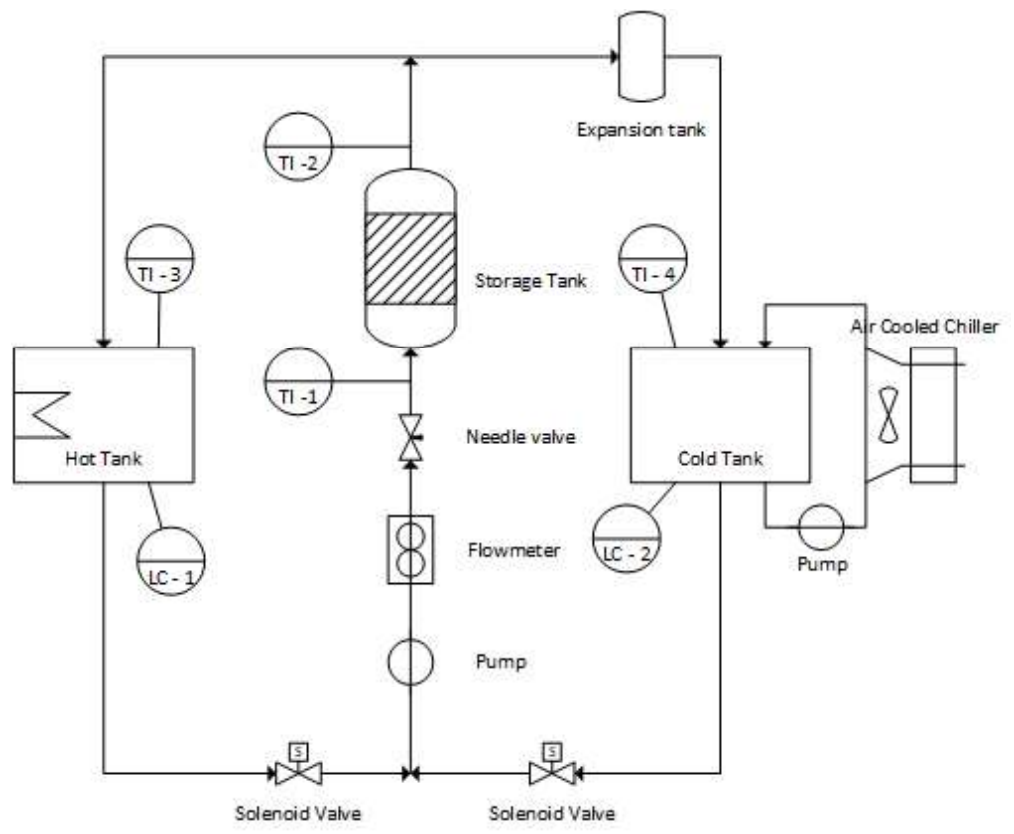

Figure 3 : Test bed piping and instrumentation diagram

[single column]

The storage tank is filled with 1408 CENG-MCP capsules (Figure 5), representing a latent energy storage capacity of $520 \mathrm{MJ}$. In order to obtain a uniform flow within the packed bed, 
two grids are installed at the inlet and at the outlet of the cylindrical parts of the storage tank. The tank is insulated with $30 \mathrm{~mm}$ thickness polyurethane foam. The size of the tank is displayed in Figure 4 and

\begin{tabular}{|c|c|c|}
\hline Cylindrical part & Height $(\mathrm{m})$ & 0.2 \\
\cline { 2 - 3 } & Diameter $(\mathrm{m})$ & 0.2 \\
\hline Conical part & Height $(\mathrm{m})$ & 0.09 \\
\hline \multicolumn{2}{|c|}{ Stainless steel thickness (mm) } & 2 \\
\hline
\end{tabular}

Table 2 while the tank filling materials properties are presented in Table 3.

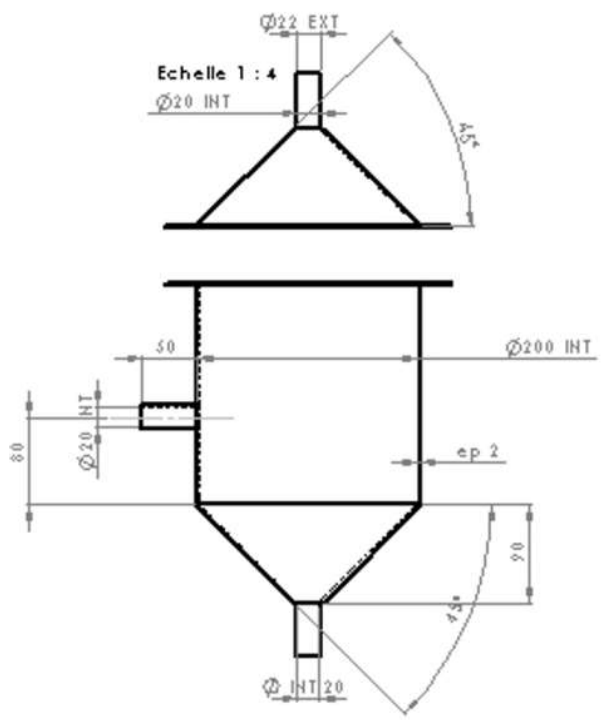

Figure 4 : Storage tank layout

[single column]

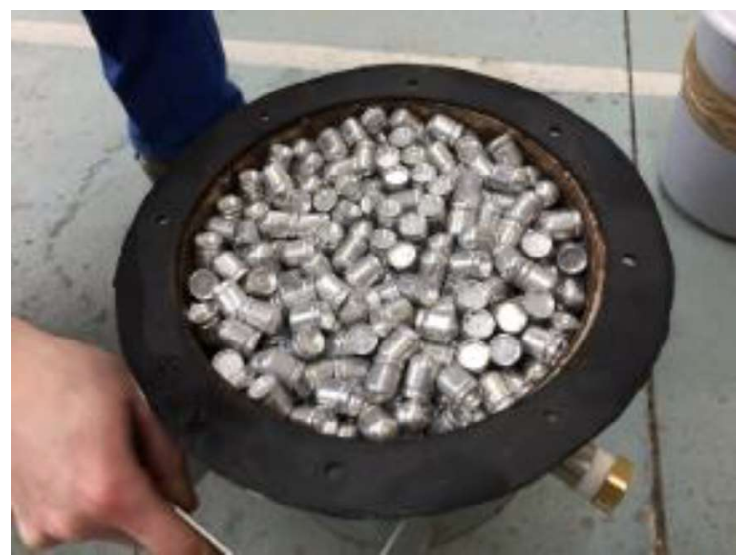

Figure 5 : Storage tank filled with CENG-PCM capsules

[single column]

\begin{tabular}{|c|c|c|}
\hline Cylindrical part & Height $(\mathrm{m})$ & 0.2 \\
\cline { 2 - 3 } & Diameter $(\mathrm{m})$ & 0.2 \\
\hline Conical part & Height $(\mathrm{m})$ & 0.09 \\
\hline \multicolumn{2}{|c|}{ Stainless steel thickness $(\mathrm{mm})$} & 2 \\
\hline
\end{tabular}




\begin{tabular}{|c|c|c|}
\hline & $\mathrm{C}_{\mathrm{p}}(\mathrm{J} / \mathrm{kg} . \mathrm{K})$ & Weight $(\mathrm{kg})$ \\
\hline Water within the storage tank & 4186 & 4.8 \\
\hline Aluminium & 897 & 1.45 \\
\hline Stainless steel & 500 & 4 \\
\hline PCM & 2000 & 2 \\
\hline CENG & 1800 & 0.5 \\
\hline
\end{tabular}

Table 3 : Material weight and heat capacity of the storage tank

\subsection{Metrology}

The temperatures have been measured at the inlet and the outlet of the storage tank with $3 \mathrm{~mm}$ B class PT100 sensors. The hot and cold water tank temperatures are acquired using $1 \mathrm{~mm} \mathrm{~K}$ type thermocouples. All the sensors have been calibrated before starting the cycles. The flow rate has been measured by an Endress+Hauser Promag 10H15 electromagnetic flowmeter. All the data were recorded every second via an ARDUINO interface to a PC.

\subsection{Experimental procedure}

\subsubsection{Aggregated parameters}

The heat transfer rate $\phi$ has been calculated using the inlet temperature $T_{i n}$, the outlet temperature $T_{\text {out, }}$ the volumetric flow rate $q$, the density $\rho$ and the heat capacity $C_{p}$ of the water at the average temperature ( Equation 1).

$$
\varnothing=\rho . q . C_{p} \cdot\left(T_{o u t}-T_{\text {in }}\right) \quad \text { Equation } 1
$$

The energy stored $E_{\text {stored }}$ for each phase, heating and cooling, has been calculated from the heat transfer rate $\phi$ and the time step $\Delta t$ (Equation 2).

$$
E_{\text {stored }}=\sum_{t_{0}}^{t_{\text {end }}} \emptyset . \Delta t \quad \text { Equation } 2
$$

Where $t_{0}$ denotes the starting time of the phase and $t_{e n d}$, the end time.

The measurement uncertainties of the aggregated parameters are assessed to be less than $10 \%$. The major uncertainties are on the temperature difference at the end of cooling or heating cycle when this difference is small: $0.9 \mathrm{~K}$.

\subsubsection{Heat losses assessment}

A first run without PCM-CENG capsules has been performed in order to measure the heat losses of the storage tank. The heat transfer rate has been measured with a water flow at the maximum 
operating temperature: $85^{\circ} \mathrm{C}$. The maximum heat losses were measured at $350 \mathrm{~W}$ without insulation and $100 \mathrm{~W}$ with insulation. This value is reasonably small compared to the average heat transfer rate between the capsules and the HTF, larger than $5000 \mathrm{~W}$, during the test.

\subsubsection{Cycling procedure}

The tests were performed from April to June 2018. The test bed was running 24 hours a day, 7 days a week schedule. The first 1000 half-cycles were dedicated for tuning the duration of each cycle.

The conditions required for changing phase from cold to hot or hot to cold half-cycle were the following. First, the temperatures difference between the inlet and the outlet had to be less than $0.9 \mathrm{~K}$. This was equivalent to commute when the heat flow rate was less than $800 \mathrm{~W}$. The second additional condition was based on the temperatures of the hot and cold tanks. The temperature of the cold tank had to be less than $40^{\circ} \mathrm{C}$ before starting the cooling half-cycle. Similarly, the temperature of the hot tank had to be more than $84^{\circ} \mathrm{C}$ before starting the heating half-cycle.

The test bed was settled in a warehouse with uncontrolled ambient temperature. Therefore, the water air cooling process was affected by the external temperature variations: night/day, hot/cold days. However, the minimum and maximum temperatures of thermal cycles were reached at each cycle allowing the complete phase change. Even if, the durations of the cycle fluctuated (Figure 10), the CENG-PCM samples experienced the same phenomenon at each cycle. The tests were stopped several times for the maintenance of the electrical box. Also, we observed that some capsules were not perfectly sealed. Therefore, a small quantity of paraffin, approximatively 5 grams, escaped from the storage tank. The lost paraffin settled in the cold parts of the test bed, including in the solenoid valve. This paraffin deposit provoked a failure in fully closing the cold water valve when operating a heating half cycle. These failures happened several times for half-cycles around number 15000.

\section{Results and discussions}

\subsection{Samples observation}

A PCM-CENG sample before and after thermal cycling is shown in Figure 6 and Figure 7. On the new sample, we can observe the thermal grease at the top of the aluminium shell. After aging, a withe paste coated completely the internal wall of the shell. This paste was a mix of 
paraffin and thermal conductive grease. Therefore, despite some space left in the shell to allow the matrix to expand freely, some paraffin migrated at the surface of the CENG. In addition, we can observe a delamination of the CENG structure. As expected, the thermal expansion of the paraffin weakened the bonds that keep together the graphite layers.

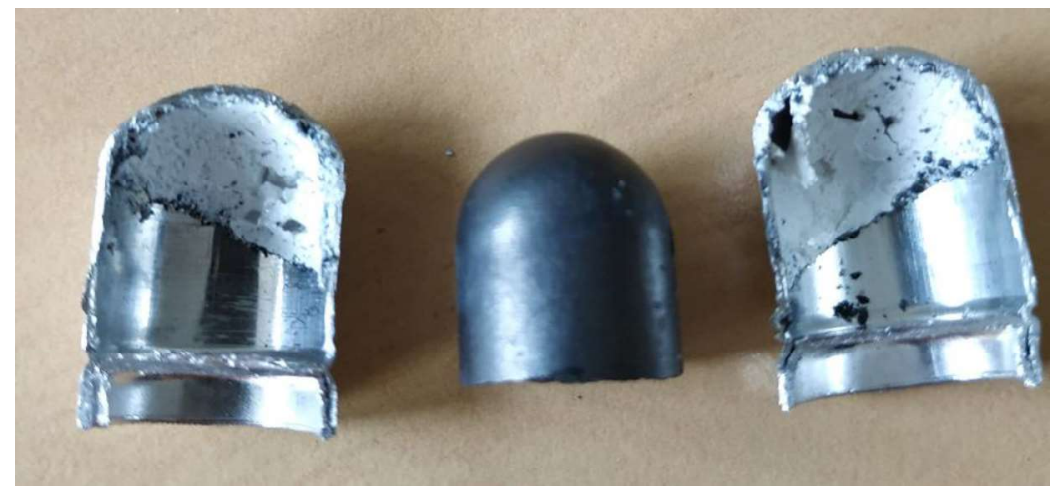

Figure 6 : Picture of an open CENG-PCM-Aluminium capsules

[single column]

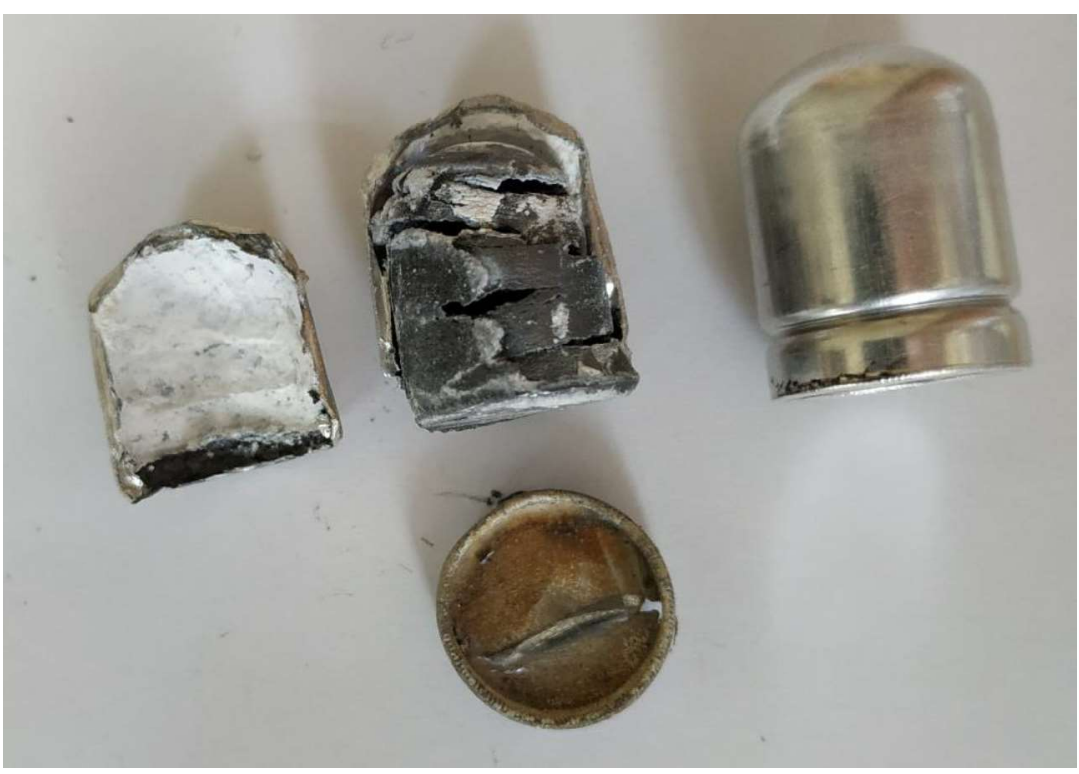

Figure 7 : Capsules opened after ageing test [single column]

\subsection{Cycle analysis}

We will call in this section each cooling or heating phase, a "half cycle". The full thermal cycle includes a heating and a cooling "half cycle".

\subsubsection{Temperature and heat transfer rate analysis}


The heat transfer rate and the temperature evolution at the inlet and outlet of the storage tank and the temperatures of the hot and cold water tanks are plotted for two half-cycles in Figure 8. The hot water tank remains at the same temperature during the cooling phase. Its temperature drops at the beginning of the heating phase from $85{ }^{\circ} \mathrm{C}$ to $75^{\circ} \mathrm{C}$ because the cold water evacuated from storage tank comes in the hot tank. The hot tank temperature rises during the heating cycle tanks to the supply of the $6 \mathrm{~kW}$ electrical resistance. The small temperature fluctuations observed in the hot tank are due to the natural convection within the tank. The cold-water tank is at $35^{\circ} \mathrm{C}$ before the cooling phase starts. This initial temperature depends on the external ambient temperature because the cooling capacity depends on an air chilling system. The cold tank temperature increases when the hot water from the storage tank enters to the tank. Then, the temperature of the cold tank decreases with a slope depending on the external ambient temperature.

The phase change temperature of the composite is around $70{ }^{\circ} \mathrm{C}$. Therefore, the temperature difference between the Heat Transfer Fluid (HTF) and the PCM is larger during the cooling phase, around $25 \mathrm{~K}$, compared to the heating phase, $10 \mathrm{~K}$. We can then expect that the duration of the cooling cycles will be shorter.

The inlet temperature varies from 85 to $40{ }^{\circ} \mathrm{C}$ and follows the hot or cold tank temperatures with a difference around $2-3 \mathrm{~K}$. The temperature difference between inlet and outlet is very important at the beginning of each cycle due to the replacement of the HTF within the tank. Indeed, the outflow keeps the same temperature while the inlet flow temperature changes sharply. This phase duration, around 25 seconds, corresponds to the HTF transit time within the tank. At the end of this phase, the heat transfer rate is maximum.

After this maximum heat transfer rate, the inlet temperature changes gently because of the hot and cold tank temperatures variation, while the outlet temperature varies sharply. Then, the heat transfer rate decreases progressively to reach a constant value stage where the heat transfer represents mainly the heat exchange between the capsules and the HTF.

When the heat transfer rate is lower than $800 \mathrm{~W}$, the half-cycle ends. 


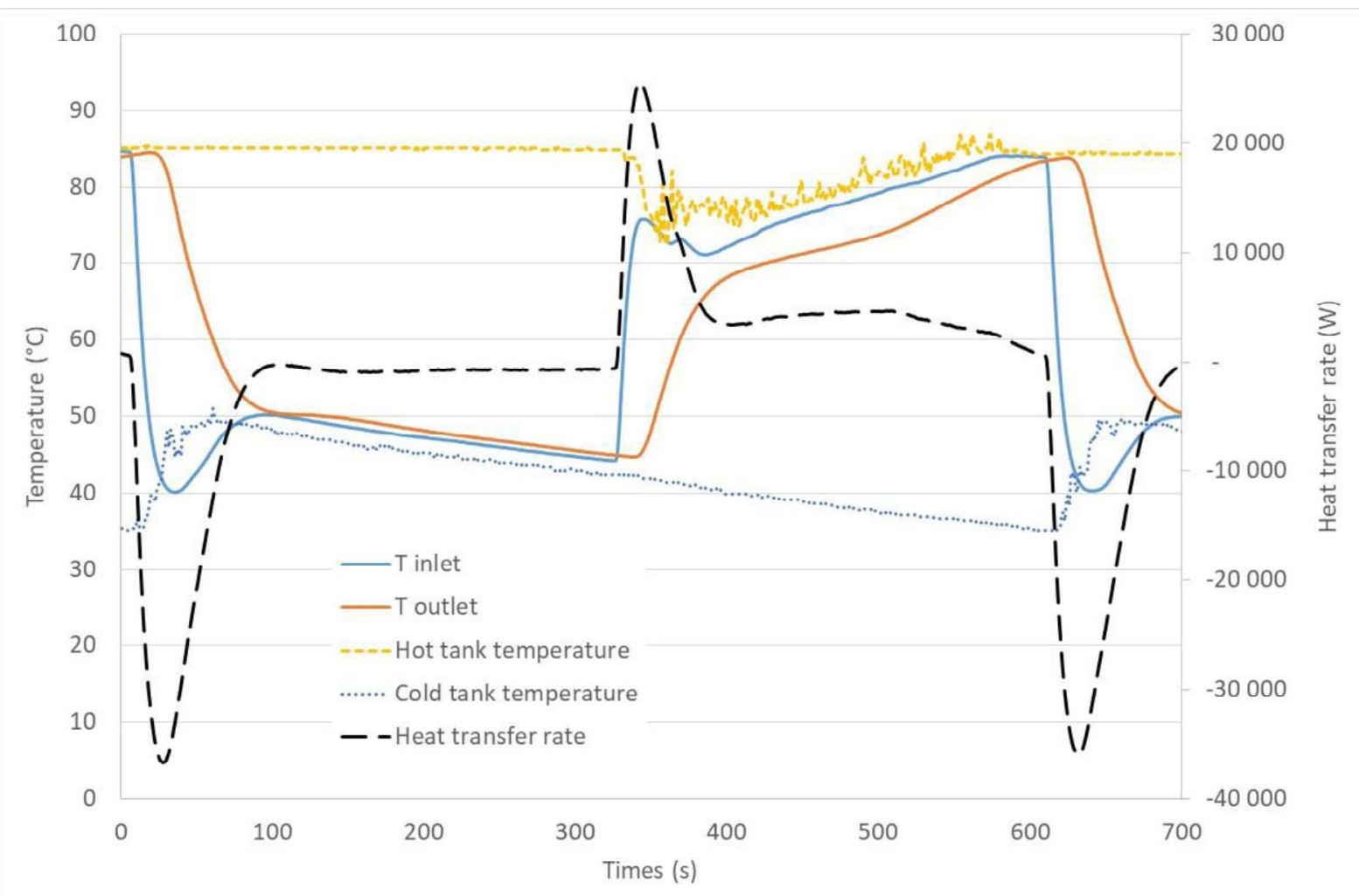

Figure 8: Temperatures variations for half-cycle numbers 1450 and 1451

[single column]

\subsubsection{Energy balance analysis within a cycle}

The Figure 9 displays the energy stored or released during the cycling. The first half cycle displayed is a cooling phase where the PCM solidifies. The total energy is calculated from the experimental data with

Equation 1. The sensible energy $E_{\text {sensible }}$ is calculated (

Equation 3) from the average temperature $T_{\text {average }}$ within the storage tank (

Equation 4) and the weight of water within the tank $m_{\text {water }}$, the weight of aluminium of the capsules $m_{a l u}$, the weight of stainless steel of the storage tank $m_{t a n k}$, the weight of paraffin $m_{P C M}$. The weights and heat capacities are given in Table 3 and $t_{0}$ denotes the time at the beginning of the phase.

$$
\begin{gathered}
E_{\text {sensible }}\left(t_{0} \rightarrow t\right)=\left(m_{\text {water }} \cdot C_{p, \text { water }}+m_{\text {alu }} \cdot C_{p, \text { alu }}+m_{\text {tank }} \cdot C_{p, \text { tank }}+m_{P C M} \cdot C_{p, P C M}+\right. \\
\left.m_{C E N G} \cdot C_{p, C E N G}\right) \cdot\left(T_{\text {average }}(t)-T_{\text {average }}\left(t_{0}\right)\right)
\end{gathered}
$$

We assume that all the components are at the same average temperature $T_{\text {average: }}$ :

$$
T_{\text {average }}(t)=\frac{1}{2}\left(T_{\text {inlet }}(t)+T_{\text {outlet }}(t)\right) \quad \text { Equation } 4
$$

The latent energy $E_{\text {stored }}$ (Equation 5) is deduced from the total energy $E_{\text {store }}$ and the sensible energy $E_{\text {sensible: }}$ : 


$$
E_{\text {latent }}=E_{\text {stored }}-E_{\text {sensible }} \quad \text { Equation } 5
$$

We can first note on Figure 9, that the total energy is conserved during the cycles. The losses at the walls are negligible from one cycle to the other one. The latent energy evolution shows that the PCM solidifies in 80 seconds approximatively and melts in around 200 seconds. This phenomenon can be explained by the average temperature difference between the HTF and the phase change temperature of $70{ }^{\circ} \mathrm{C}$. This difference is around $25 \mathrm{~K}$ in cooling phase versus 10 $\mathrm{K}$ during heating phase. Also, we can observe at the end of each phase, that latent energy found experimentally is very close to the theoretical value. It proves that the phase change operated completely. At last, we can observe that the latent energy represents only $30 \%$ of the total energy.

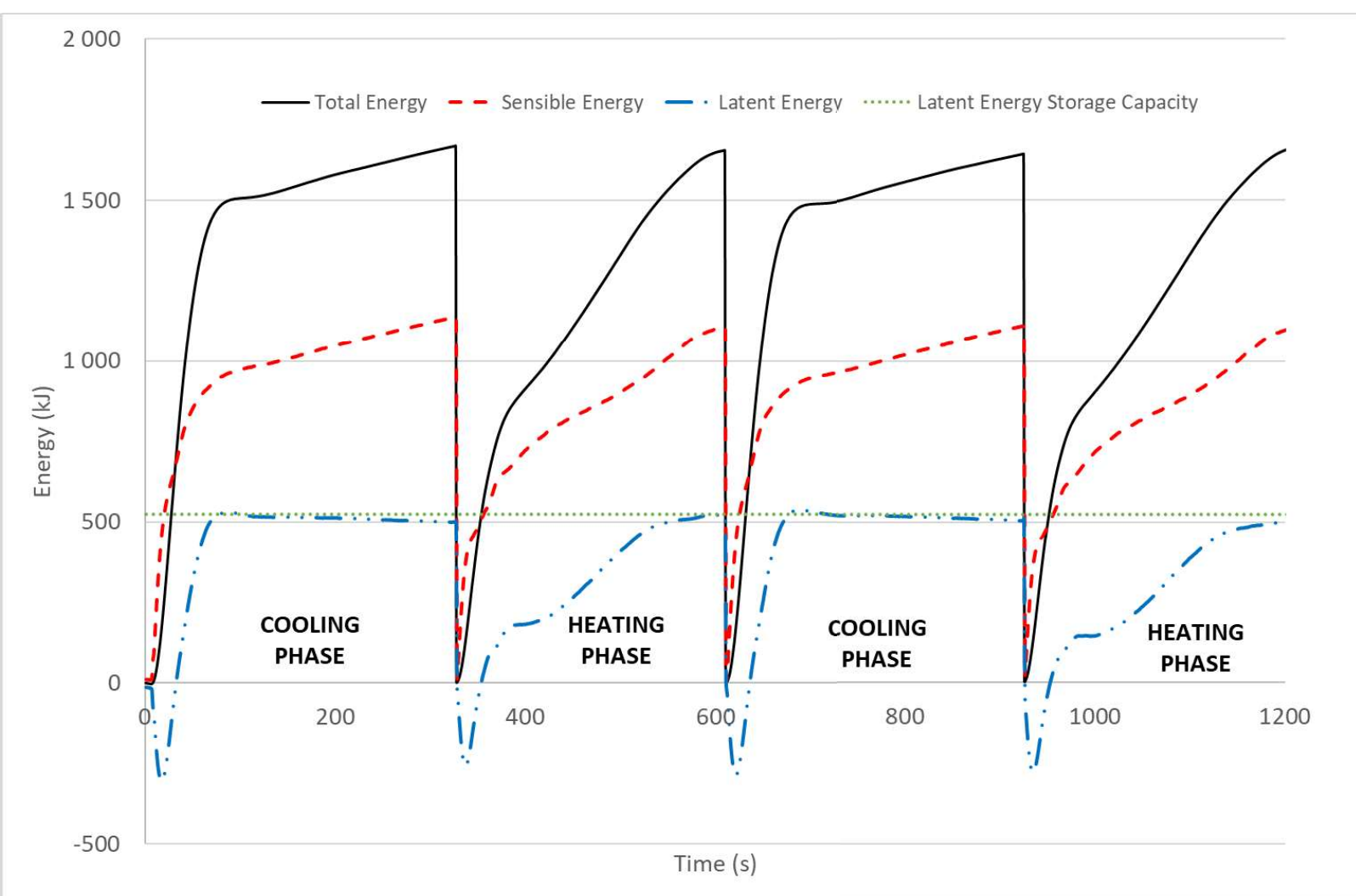

Figure 9: Energy variation during heating and cooling phase for four half-cycles 1450, 1451, 1452 and 1454

[single column]

The durations of the cycles are plotted in Figure 10. The duration of the heating cycle is relatively stable compared to the cooling cycles: $20 \%$ variation for the heating cycles versus $100 \%$ for the cooling ones. The oscillations, more visible on the cooling phase plots, are correlated to the external temperature variations. Typically, an oscillation represents a day of 
test. These typical fluctuations are also visible in Figure 11 that plots the evolution of the average heat transfer rate for each phase.

\subsubsection{Heat transfer analysis}

The average heat transfer rate (Figure 11) varies in the same order of the durations of the cycles. The fluctuations are due to the uncertainties of the measurement, to the variation of the flowrate of $5-6 \%$, and, for the cooling cycles only, to the external temperature fluctuations. If we focus on the heating cycles, the average heat transfer rate trend line seems to be unchanged from the beginning of the aging test until the end. The conservation of the heat transfer rate seems to demonstrate that the effective thermal conductivity of the composite is not affected by the delamination of the CENG. This result could be expected. Indeed, the delamination affects mainly the axial heat transfer while the planar should remain the same. Moreover, the thermal conductivity of the CENG-PCM is already three times larger in the planar direction before delamination. Therefore, the heat transfer occurs mainly in the planar direction.

An average heat transfer coefficient has been calculated for a heating cycle before and after aging. A difference less than $4 \%$ has been found between the two values: $394 \mathrm{~W} \cdot \mathrm{m}^{-2} \cdot \mathrm{K}^{-1}$ before aging and $377 \mathrm{~W} \cdot \mathrm{m}^{-2} \cdot \mathrm{K}^{-1}$ after aging. In both cases, the heat transfer has been calculated when the heat transfer rate was nearly constant over 100 seconds. During this period, the PCM should change phase and its temperature should be nearly constant. Therefore, the temperature difference has been taken between the average water temperature $T_{\text {average }}$ and the phase change temperature $70^{\circ} \mathrm{C}$.

\subsubsection{Energy conservation}

The stored energy evolution is plotted in Figure 12 and Figure 13. Again, we observe a fluctuation mainly due to uncontrolled cooling temperatures, which affect the maximum temperatures reached by the storage and then, the sensible energy. However, we do not observe any significant changes between the first cycles and the last cycles. However, as seen before, the total energy calculated contains more than $70 \%$ of sensible energy. In consequence, a reduction of the latent heat storage capacity might be not visible in the total energy evolution. 


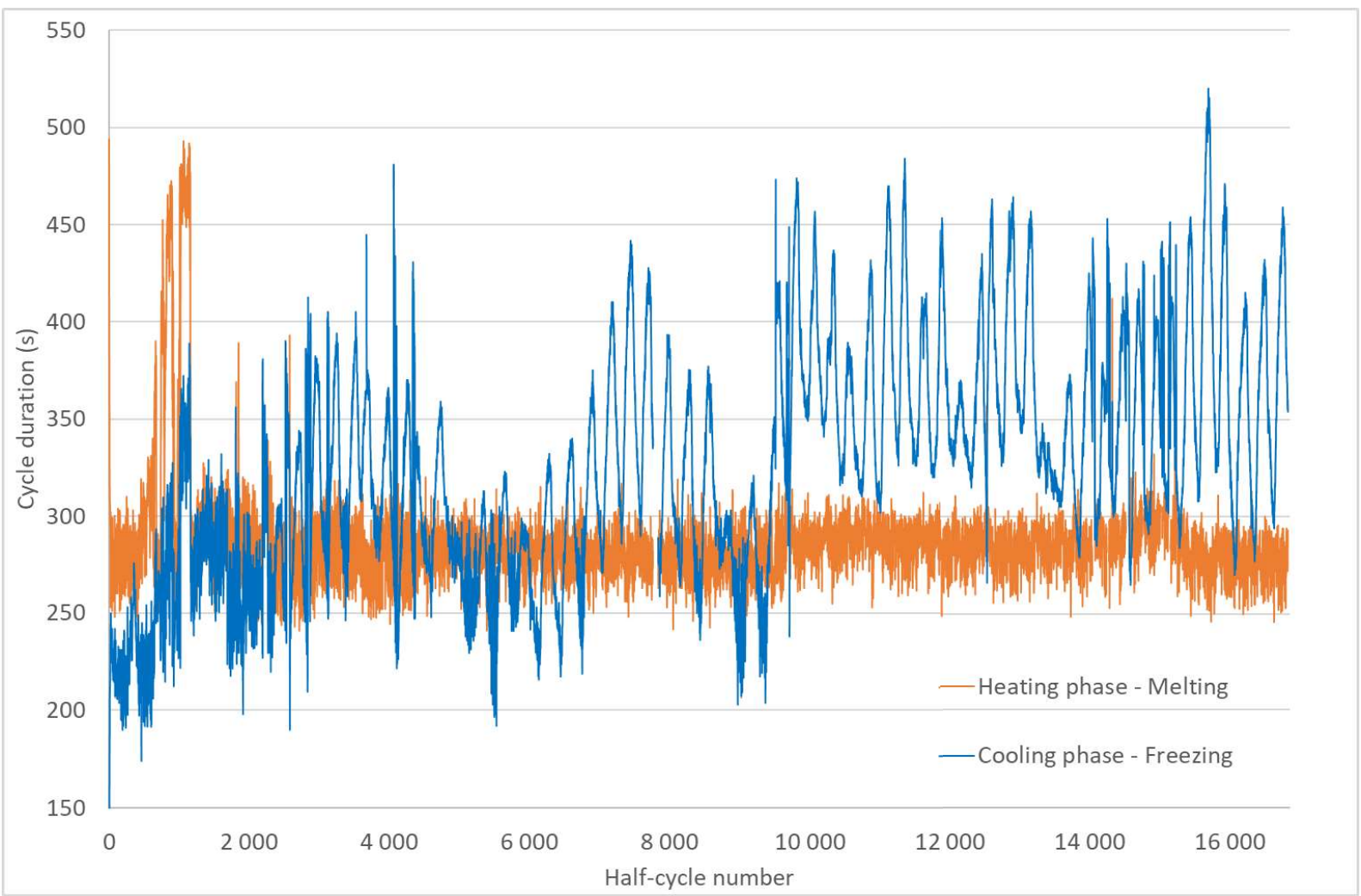

Figure 10 : Half-cycle duration for heating and melting phases

[single column]

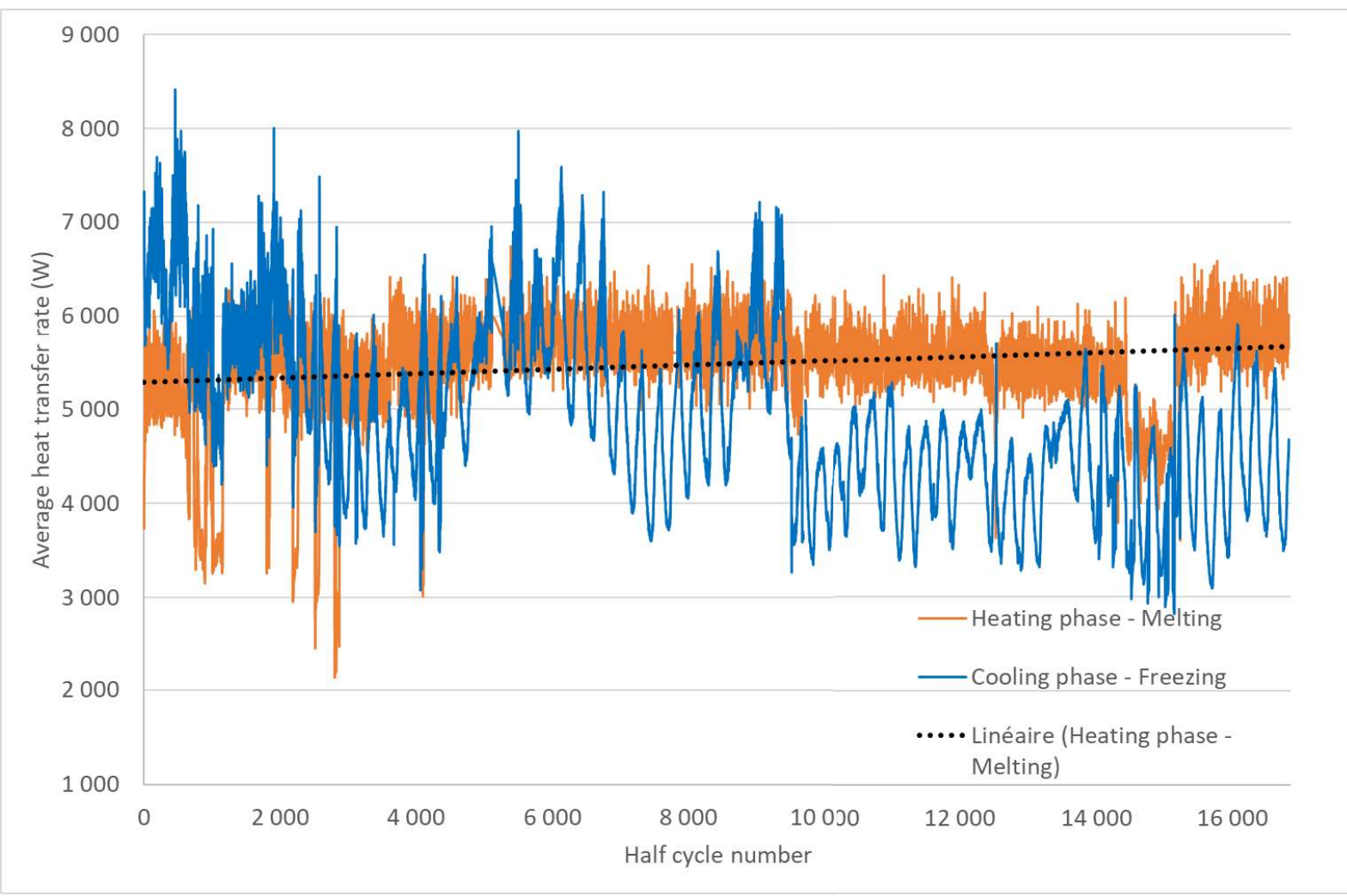

Figure 11 : Average heat transfer rate during each 17000 heating and cooling half-cycles

[single column] 


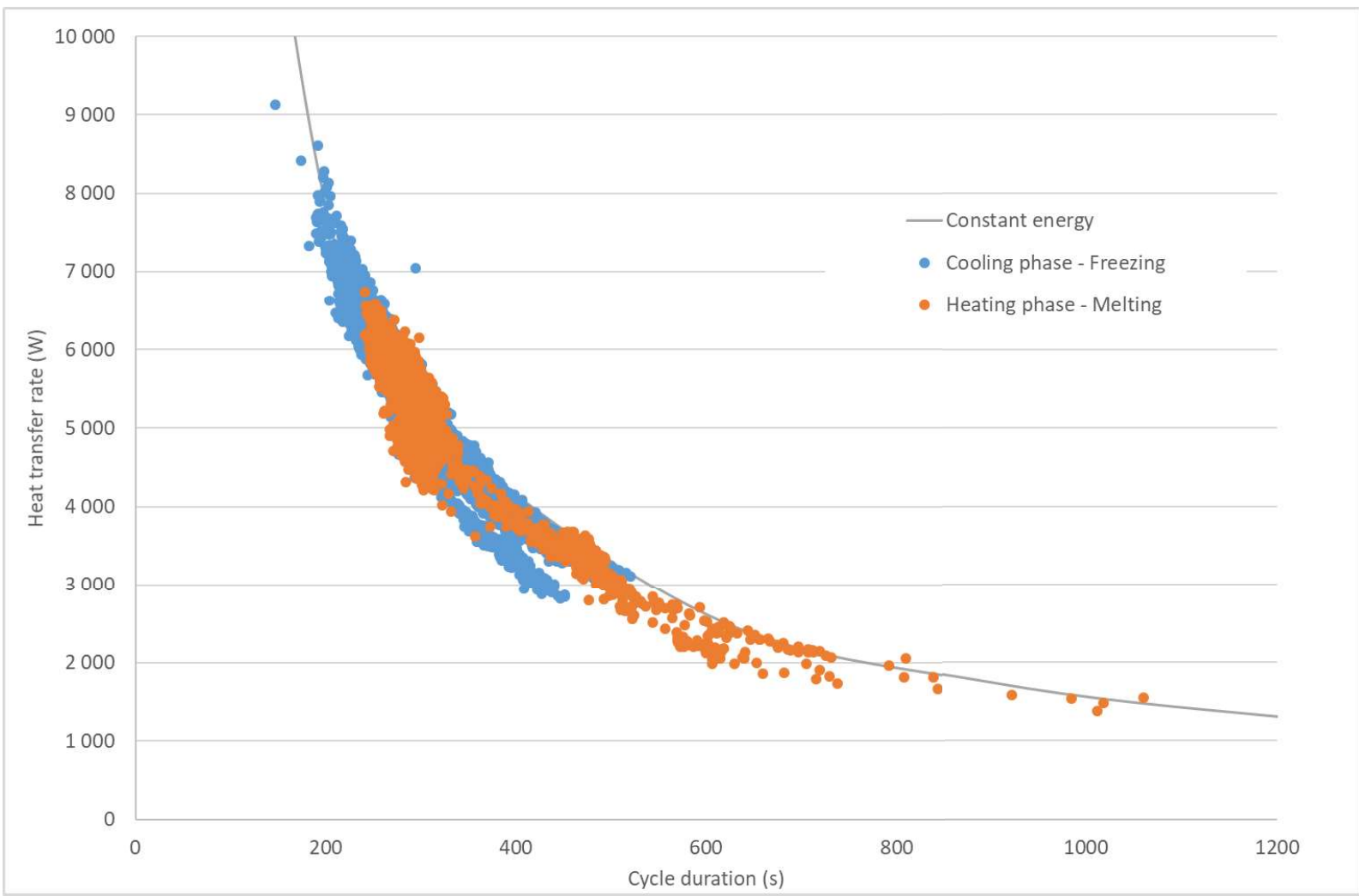

Figure $12:$ Average heat transfer rate for each half-cycle duration for heating and cooling phase.

[single column]

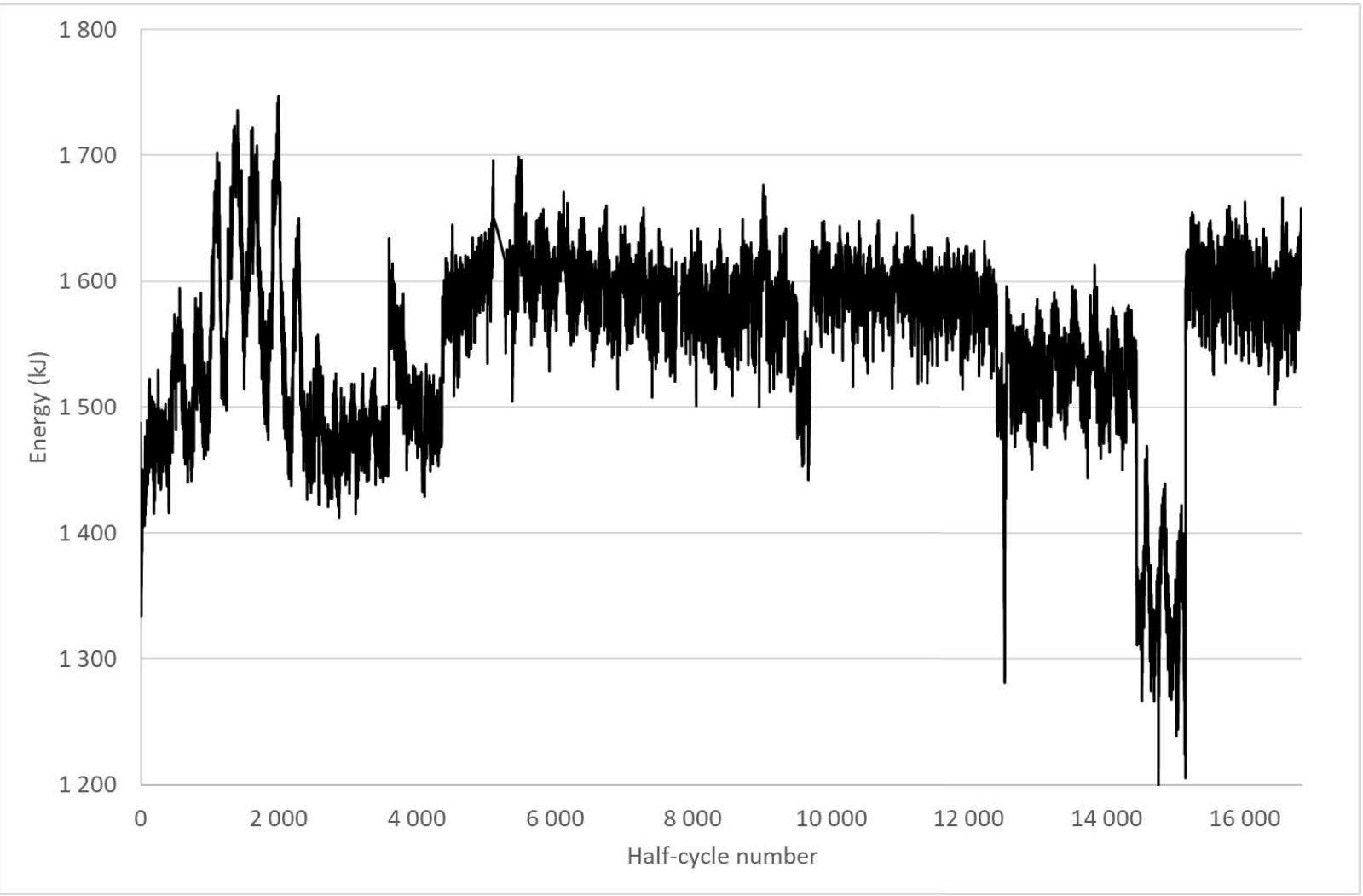

Figure 13 : Energy transferred at each half-cycle

[single column] 


\subsubsection{Thermal properties}

In order to assess the thermal storage capacity evolution, a Differential Scanning Calorimetry (DSC) analysis was performed on the PCM (Figure 14). The PCM was extracted from the CENG by heating and pressing the composite. The liquid extracted was composed from mostly of paraffin and a small amount of thermal grease. The two components could not be separated. This sample was compared to unused new paraffin. The DSC was carried out on respectively $2.5 \mathrm{mg}$ and $3.6 \mathrm{mg}$ samples of aged and new paraffin, between $30^{\circ} \mathrm{C}$ and $90^{\circ} \mathrm{C}$ at $8 \mathrm{~K} / \mathrm{min}$. The melting and solidification onset temperatures were determined by taking the intersections of the baselines with the tangents at the inflection points of the DSC pikes which are the equivalent to the maximum slopes of the pikes. The results, given in Table 4, show that the temperatures of phase change in melting and solidification remain identical. The difference between the latent heat is less than $10 \%$. This difference might be due to the decrease of the latent heat capacity or, more probably, due to the impure mixing of the aged paraffin with the thermal grease. Indeed, the presence of thermal grease does not contribute to the latent heat, but it counts in the total mass of the sample. Therefore, the latent heat of the mixing is inevitably reduced. In consequence, we can claim that the thermal cycling does not affect significantly the thermal storage capacity of the composite. 


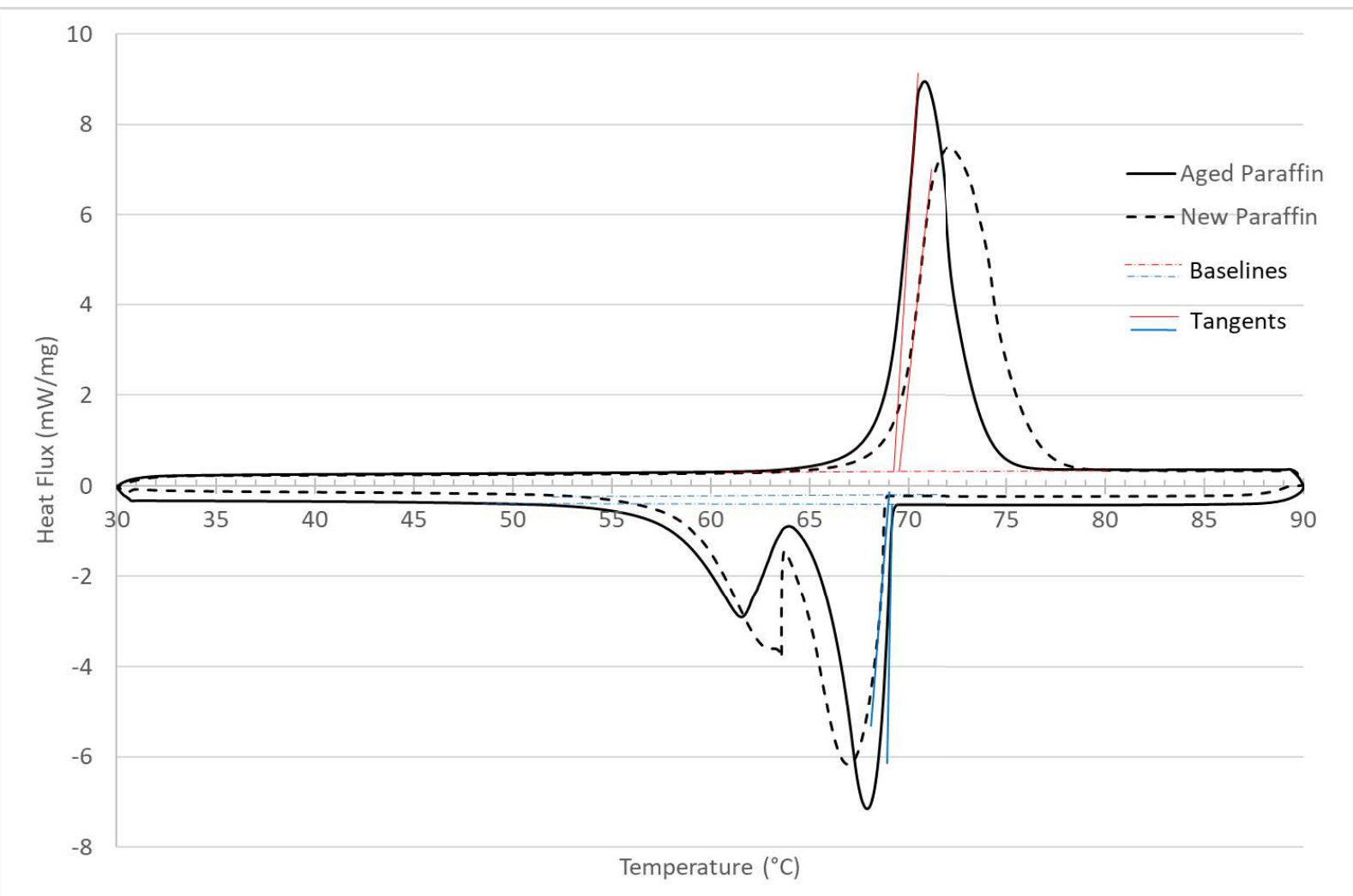

Figure $14: D S C$ analysis with aged and new RT70HC paraffin including base lines and tangents to determine the onset melting (in red) and solidification (in blue) temperatures

[single column]

\begin{tabular}{|c|c|c|c|}
\hline & $\begin{array}{c}\text { Melting } \\
\text { temperature }\end{array}$ & $\begin{array}{l}\text { Solidification } \\
\text { temperature }\end{array}$ & Latent heat \\
\hline New PCM & $69.5^{\circ} \mathrm{C}$ & $68.8^{\circ} \mathrm{C}$ & $257 \mathrm{~J}^{-g^{-1}}$ \\
\hline Aged PCM & $69.2^{\circ} \mathrm{C}$ & $69^{\circ} \mathrm{C}$ & $230 \mathrm{J.g}^{-1}$ \\
\hline
\end{tabular}

\subsection{FTIR Spectra analysis}

A Fourier Transform InfraRed spectroscopy (FTIR) has been performed on new and aged paraffins (Figure 15). Both spectra are very similar with identical pikes at the same frequencies. This analysis shows that no new species appeared during the aging test, demonstrating the chemical stability of the paraffin. 


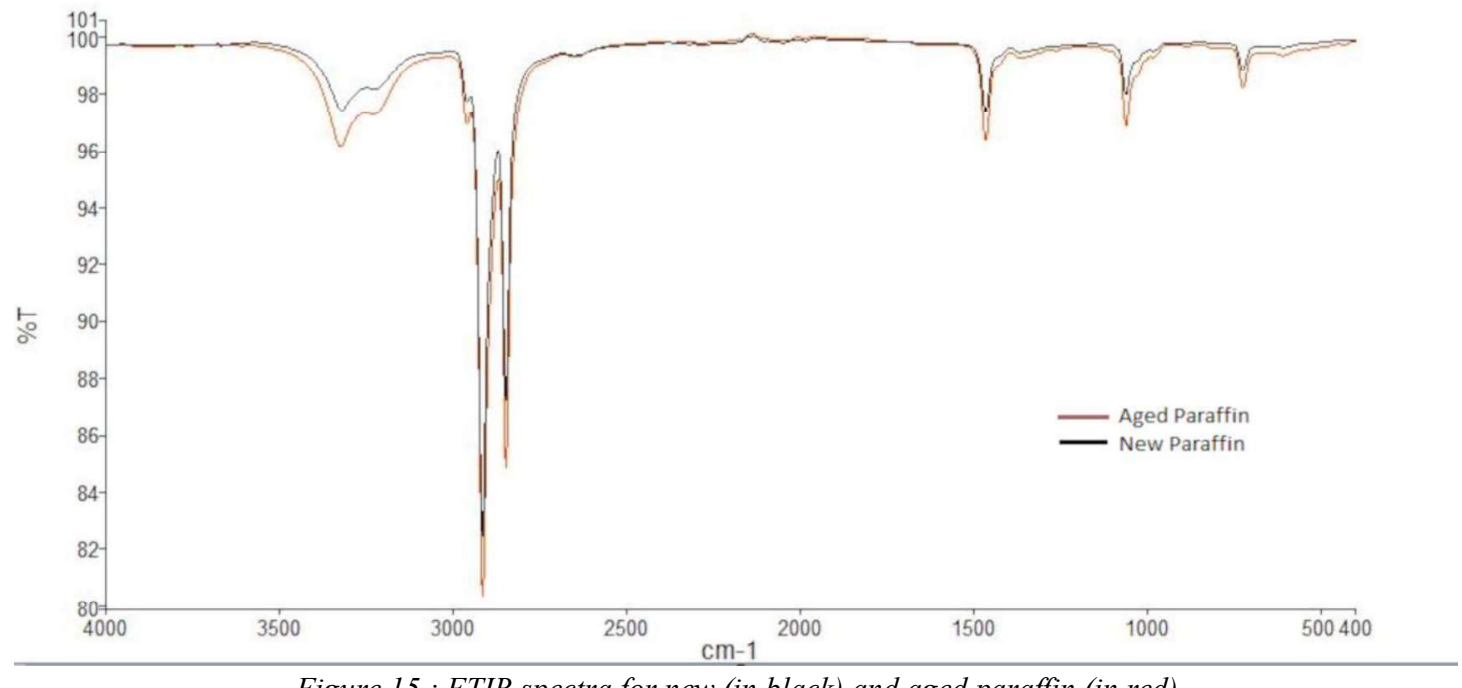

Figure 15 : FTIR spectra for new (in black) and aged paraffin (in red)

[single column]

\section{Conclusion}

Compressed ENG paraffin encapsulated in aluminium shells has been thermally aged by applying more than 8500 heating and cooling cycles. After the aging process, we observed a delamination of the CENG structure inside the shell. This deterioration was probably the consequence of the successive thermal expansions of the structure. However, no significant change in heat transfer rate from the storage material to the fluid has been measured. The heat transfer capacity stability is undoubtedly due to the heat transfer which was affected only on the direction of the compression while the heat transfer occurs mainly along the planar direction.

According to the DSC analysis, the thermal storage capacity of the CENG-PCM seems to remain almost unchanged during the aging process. The DSC analysis has shown that the phase change temperatures were not affected by the thermal cycling. Finally, the FTIR analysis did not reveal any appearance of a new species.

In conclusion, we can say that the CENG-RT70HC encapsulated in aluminium shell can endure more than 8500 thermal cycles without significant reduction of its thermal properties.

\section{Acknowledgements}

The authors would like to acknowledge Arthur Parlier, Julien De Bonnières, Xavier Libaud, Mayeul De Lanzac and Pierre-Alexandre Quinault for their work during their internship at Icam, Alex Lejeau and Bruno Bes for their technical support, and Fabrice Chopart from HUTCHNSON. 


\section{Funding}

This work was supported by the ERDF CIPITAP programme 2014-2020 Pays de la Loire, by the French Environment and Energy Management Agency ADEME and the Pays de la Loire Region.

\section{References}

[1] M.E. Zayed, J. Zhao, A.H. Elsheikh, F.A. Hammad, L. Ma, Y. Du, A.E. Kabeel, S.M. Shalaby, Solar Energy Materials and Solar Cells Applications of cascaded phase change materials in solar water collector storage tanks : A review, Sol. Energy Mater. Sol. Cells. 199 (2019) 24-49. https://doi.org/10.1016/j.solmat.2019.04.018.

[2] B. Stutz, N. Le Pierres, F. Kuznik, K. Johannes, E. Palomo Del Barrio, J.-P. Bédécarrats, S. Gibout, P. Marty, L. Zalewski, J. Soto, N. Mazet, R. Olives, J.-J. Bezian, D.P. Minh, Storage of thermal solar energy, Comptes Rendus Phys. 18 (2017). https://doi.org/10.1016/j.crhy.2017.09.008.

[3] B. Xu, P. Li, C. Chan, Application of phase change materials for thermal energy storage in concentrated solar thermal power plants: A review to recent developments, Appl. Energy. 160 (2015) 286-307. https://doi.org/10.1016/j.apenergy.2015.09.016.

[4] J.M.P.Q. Delgado, J.C. Martinho, A. Vaz Sá, A.S. Guimarães, V. Abrantes, Thermal Energy Storage with Phase Change Materials, A Literature Review of Applications for Buildings Materials, 2019. https://doi.org/10.1007/978-3-319-97499-6.

[5] F. Kuznik, D. David, K. Johannes, J.J. Roux, A review on phase change materials integrated in building walls, Renew. Sustain. Energy Rev. 15 (2011) 379-391. https://doi.org/10.1016/j.rser.2010.08.019.

[6] L.F. Cabeza, a. Castell, C. Barreneche, a. De Gracia, a. I. Fernández, Materials used as PCM in thermal energy storage in buildings: A review, Renew. Sustain. Energy Rev. 15 (2011) 1675-1695. https://doi.org/10.1016/j.rser.2010.11.018.

[7] H. Mehling, L.F. Cabeza, S. Hippeli, S. Hiebler, PCM-module to improve hot water heat stores with stratification, 28 (2003) 699-711.

[8] L.T. Wong, K.W. Mui, Y. Guan, Shower water heat recovery in high-rise residential buildings of Hong Kong, Appl. Energy. 87 (2010) 703-709. https://doi.org/10.1016/j.apenergy.2009.08.008.

[9] Q. Ren, P. Guo, J. Zhu, International Journal of Heat and Mass Transfer Thermal management of electronic devices using pin-fin based cascade microencapsulated PCM 
/ expanded graphite composite, 149 (2020) 1-16.

https://doi.org/10.1016/j.jiheatmasstransfer.2019.119199.

[10] H. Muhammad, A. Arshad, M. Jabbal, P.G. Verdin, International Journal of Heat and Mass Transfer Thermal management of electronics devices with PCMs filled pin-fin heat sinks : A comparison, Int. J. Heat Mass Transf. 117 (2018) 1199-1204. https://doi.org/10.1016/j.ijheatmasstransfer.2017.10.065.

[11] S. Kumar, M.K. Das, P. Rath, Application of TCE-PCM based heat sinks for cooling of electronic components : A review, Elsevier, 2016. https://doi.org/10.1016/j.rser.2015.12.238.

[12] Z. Ling, Z. Zhang, G. Shi, X. Fang, L. Wang, X. Gao, Y. Fang, T. Xu, S. Wang, X. Liu, Review on thermal management systems using phase change materials for electronic components, Li-ion batteries and photovoltaic modules, Renew. Sustain. Energy Rev. 31 (2014) 427-438. https://doi.org/10.1016/j.rser.2013.12.017.

[13] S. Mondal, Phase change materials for smart textiles - An overview, Appl. Therm. Eng. 28 (2008) 1536-1550. https://doi.org/10.1016/j.applthermaleng.2007.08.009.

[14] S. Landini, J. Leworthy, T.S. O'Donovan, A Review of Phase Change Materials for the Thermal Management and Isothermalisation of Lithium-Ion Cells, J. Energy Storage. 25 (2019) 100887. https://doi.org/10.1016/j.est.2019.100887.

[15] J. Jaguemont, N. Omar, P. Van den Bossche, J. Mierlo, Phase-change materials (PCM) for automotive applications: A review, Appl. Therm. Eng. 132 (2018) 308-320. https://doi.org/10.1016/j.applthermaleng.2017.12.097.

[16] H. Fathabadi, High thermal performance lithium-ion battery pack including hybrid active-passive thermal management system for using in hybrid/electric vehicles, Energy. 70 (2014) 529-538. https://doi.org/10.1016/j.energy.2014.04.046.

[17] M. Gumus, Reducing cold-start emission from internal combustion engines by means of thermal energy storage system, Appl. Therm. Eng. 29 (2009) 652-660. https://doi.org/10.1016/j.applthermaleng.2008.03.044.

[18] P. Royo, L. Acevedo, V.J. Ferreira, T. García-armingol, M.L. Ana, High-temperature PCM-based thermal energy storage for industrial furnaces installed in energy-intensive industries, 173 (2019) 1030-1040. https://doi.org/10.1016/j.energy.2019.02.118.

[19] L. Miró, J. Gasia, L.F. Cabeza, Thermal energy storage (TES) for industrial waste heat (IWH) recovery: A review, Appl. Energy. 179 (2016) 284-301. https://doi.org/10.1016/j.apenergy.2016.06.147.

[20] K. Merlin, J. Soto, D. Delaunay, L. Traonvouez, Industrial waste heat recovery using 
an enhanced conductivity latent heat thermal energy storage, Appl. Energy. 183 (2016) 491-503. https://doi.org/10.1016/j.apenergy.2016.09.007.

[21] M.K. Rathod, J. Banerjee, Thermal stability of phase change materials used in latent heat energy storage systems: A review, Renew. Sustain. Energy Rev. 18 (2013) 246258. https://doi.org/10.1016/j.rser.2012.10.022.

[22] Y.B. Tao, Y. He, A review of phase change material and performance enhancement method for latent heat storage system, 93 (2018) 245-259.

[23] M. Yuan, Y. Ren, C. Xu, F. Ye, X. Du, Characterization and stability study of a formstable erythritol/expanded graphite composite phase change material for thermal energy storage, Renew. Energy. (2019). https://doi.org/10.1016/J.RENENE.2018.12.107.

[24] S. Pincemin, R. Olives, X. Py, M. Christ, Highly conductive composites made of phase change materials and graphite for thermal storage, Sol. Energy Mater. Sol. Cells. 92 (2008) 603-613. https://doi.org/10.1016/j.solmat.2007.11.010.

[25] N. Calvet, X. Py, R. Olivès, J.P. Bédécarrats, J.P. Dumas, F. Jay, Enhanced performances of macro-encapsulated phase change materials (PCMs) by intensification of the internal effective thermal conductivity, Energy. 55 (2013) 956-964. https://doi.org/10.1016/j.energy.2013.03.078.

[26] Y. Zhong, S. Li, X. Wei, Z. Liu, Q. Guo, J. Shi, L. Liu, Heat transfer enhancement of paraffin wax using compressed expanded natural graphite for thermal energy storage, Carbon N. Y. 48 (2010) 300-304. https://doi.org/10.1016/j.carbon.2009.09.033.

[27] M. Karthik, A. Faik, P. Blanco-Rodríguez, J. Rodríguez-Aseguinolaza, B. D’Aguanno, Preparation of erythritol-graphite foam phase change composite with enhanced thermal conductivity for thermal energy storage applications, Carbon N. Y. 94 (2015) 266-276. https://doi.org/10.1016/j.carbon.2015.06.075.

[28] T. Nomura, N. Okinaka, T. Akiyama, Impregnation of porous material with phase change material for thermal energy storage, Mater. Chem. Phys. 115 (2009) 846-850. https://doi.org/10.1016/j.matchemphys.2009.02.045.

[29] Y. Ren, C. Xu, M. Yuan, F. Ye, X. Ju, X. Du, Ca ( NO 3 ) 2 -NaNO 3 / expanded graphite composite as a novel shape-stable phase change material for mid- to hightemperature thermal energy storage, Energy Convers. Manag. 163 (2018) 50-58. https://doi.org/10.1016/j.enconman.2018.02.057.

[30] G. Ma, J. Sun, Y. Zhang, Y. Jing, Y. Jia, Preparation and thermal properties of stearic acid-benzamide eutectic mixture / expanded graphite composites as phase change materials for thermal energy storage, Powder Technol. 342 (2019) 131-140. 
https://doi.org/10.1016/j.powtec.2018.09.074.

[31] Z. Huang, Z. Luo, X. Gao, X. Fang, Y. Fang, Z. Zhang, Investigations on the thermal stability, long-term reliability of LiNO $3 / \mathrm{KCl}$ - expanded graphite composite as industrial waste heat storage material and its corrosion properties with metals, Appl. Energy. 188 (2017) 521-528. https://doi.org/10.1016/j.apenergy.2016.12.010.

[32] V. Canseco, Y. Anguy, J. Josep, E. Palomo, Structural and mechanical characterization of graphite foam / phase change material composites, Carbon N. Y. 74 (2014) 266-281. https://doi.org/10.1016/j.carbon.2014.03.031.

[33] B. Zhang, Y. Tian, X. Jin, T.Y. Lo, H. Cui, Thermal and Mechanical Properties of Expanded Graphite / Paraffin Gypsum-Based Composite Material Reinforced by Carbon Fiber, (2018). https://doi.org/10.3390/ma11112205.

[34] Q. Wang, D. Zhou, Y. Chen, P. Eames, Z. Wu, Characterization and effects of thermal cycling on the properties of paraf fi $\mathrm{n} /$ expanded graphite composites, Renew. Energy. 147 (2020) 1131-1138. https://doi.org/10.1016/j.renene.2019.09.091.

[35] P.B. Salunkhe, P.S. Shembekar, A review on effect of phase change material encapsulation on the thermal performance of a system, Renew. Sustain. Energy Rev. 16 (2012) 5603-5616. https://doi.org/10.1016/j.rser.2012.05.037.

[36] C. Liu, Z. Rao, J. Zhao, Y. Huo, Y. Li, Review on nanoencapsulated phase change materials : Preparation, characterization and heat transfer enhancement, Nano Energy. 13 (2015) 814-826. https://doi.org/10.1016/j.nanoen.2015.02.016.

[37] X. Huang, C. Zhu, Y. Lin, G. Fang, Thermal properties and applications of microencapsulated PCM for thermal energy storage : A review, Appl. Therm. Eng. 147 (2019) 841-855. https://doi.org/10.1016/j.applthermaleng.2018.11.007.

[38] Z. Liu, Z. Jerry, T. Yang, D. Qin, S. Li, G. Zhang, F. Haghighat, M. Mastani, A review on macro-encapsulated phase change material for building envelope applications, Build. Environ. 144 (2018) 281-294. https://doi.org/10.1016/j.buildenv.2018.08.030.

[39] Y. Zhong, B. Zhao, J. Lin, F. Zhang, H. Wang, Z. Zhu, Z. Dai, Encapsulation of hightemperature inorganic phase change materials using graphite as heat transfer enhancer, Renew. Energy. 133 (2019) 240-247. https://doi.org/10.1016/j.renene.2018.09.107.

[40] V. Morisson, Heat transfer modelling within graphite/salt composites : From the pore scale equations to the energy storage system, Ph. D. Thesis, Univ. Bordeaux 1. (2008).

[41] X. Py, R. Olives, S. Mauran, Paraffin/porous-graphite-matrix composite as a high and constant power thermal storage material, Int. J. Heat Mass Transf. 44 (2001) 27272737. 
[42] D. Delaunay, P. Carré, Dispositif de mesure automatique de la conductivité thermique des matériaux à changement de phase, Rev. Phys. Appliquée. 17 (1982) 209-215. https://doi.org/10.1051/rphysap:01982001704020900. 